\title{
Effect of Additives in the Electrolyte on the Physical Properties of Electrodeposited Copper
}

\author{
Mitsuyoshi Matsuda ${ }^{* * *}$, Takuya Takahashi, Sachio Yoshihara* and Makoto Dobashi*** \\ *Graduate School of Engineering, Utsunomiya University, 7-1-2 Yoto, Utsunomiya-shi, Tochigi 321-8585 \\ ** Mitsui Mining \& Smelting Co.,Ltd. Corporate R\&D Center, 1333-2 Haraichi, Ageo-shi, Saitama 362-0021 \\ ****Mitsui Mining \& Smelting Co.,Ltd., 1-11-1 Osaki, Shinagawa-ku, Tokyo 141-8584
}

(Received July 29, 2009; accepted October 20, 2009)

\begin{abstract}
Copper deposited using bath additives added to the bath such as brighteners like Bis-(3-sulfopropyl)-disulfide (SPS) shows physical property changes when kept even at room temperature. In this research, the elements or groups contained in 2-Mercapto-5-benzimidazole (2M-5S), which have effects in preventing the property changes, are investigated. From this, Mercapto groups and Nitrogen atoms are thought to be essential and Benzene rings are thought to assist these effects. $2 \mathrm{M}-5 \mathrm{~S}$ is thought to produce a strong union with the $\mathrm{Cu}(\mathrm{I})$ complex and coexisting additives using $\delta$-polarized Nitrogen atoms and increases the amount of impurities incorporated into the deposits at the time of reduction. Keywords: Electrodeposited Copper, Physical Property Change, Recrystalization, Additives, Impurity, Mercapto Group, Nitrogen Atom, Benzene Ring
\end{abstract}

\section{Introduction}

Electrodeposited copper foil, which is generally used for circuit materials on Rigid Printed Circuit Boards, is produced by continuously peeling off the copper deposited from copper sulfate electrolyte on a drum-shaped rotating cathode. The peeled surface which was in contact with the drum surface replicates the smooth morphology of the cathode (drum) surface, but, in general, the other side, where copper deposition grows freely, is rough.

Recently, as electronic devices are becoming smaller, the boards contained in them are also becoming smaller and finer circuits are being required. Also, high-capacity and high-speed network communication called broadband networking is becoming common and the frequency of signals tends to higher bands. In using high-frequency signals, if the surface of a circuit is rough, signal loss becomes significant because the high frequent signal just runs through the thin area near the surface of the circuit, called the skin effect, and counter actions for reducing signal loss are required. For the above requirements, a smoother circuit surface is important.[1, 2]

As stated above, even for electrodeposited copper foil, a smoother surface is required, and the improvement of the smoothness of the side where copper deposition grows freely is important for this requirement. Controlling the crystal structure of the deposited copper using additives in the electrolyte used for the circuit-forming method in the damascene process, [3] is thought to be one countermeasure.

Copper deposited using additives to the electrolyte, such as brighteners like Bis-(3-sulfopropyl)-disulfide (SPS),[3] shows physical property changes even when kept at room temperature, though the strength of the copper just after plating is high. This phenomenon is thought to be caused by the grain growth called Self Annealing.[4]

If this time-related property changes can be controlled, a new type of electrodeposited copper foil, with strength as high as that of high-strength rolled copper alloy foils such as Colson alloy,[5] becomes possible. Through our research, adding 2-Mercapto-5-benzimidazole (2M-5S) was found to enable the achievement of both a smooth surface and no time-related changes, and 2M-5S was thought to have the effect of preventing the time-related property changes. Because the correlation between grain size and tensile strength followed the Hall-Petch equation, grain size was thought to be the most significant factor. Preventing grain growth (Self Annealing) was thought to prevent the tensile strength change. Changing the amount of the 
2M-5S added made changes in the amount of impurities such as $\mathrm{S}, \mathrm{Cl}$ contained in the copper. In accordance with these changes, the tensile strength after annealing changed, so it was thought that the impurities incorporated into the copper deposits localized at the grain boundary and prevented re-crystallization.[6]

However, there has been no research done on systematically classifying the additives which affect the physical properties such as strength from the viewpoint of the elements or groups contained in the additives. So it was not clear which elements or groups of $2 \mathrm{M}-5 \mathrm{~S}$ cause the effects. Therefore, through the investigation of the effects of additives which have structures similar to $2 \mathrm{M}-5 \mathrm{~S}$, the effects of the elements or groups contained in the additives for preventing the property change were estimated.

In addition, the behavior of additives in the electrolyte conjectured above was investigated using a rotating ringdisc electrode.

In this paper, tensile strength after annealing was used as an index of the effect of preventing the time-related property changes of the copper deposits. As mentioned above, the copper deposits discussed in this paper were confirmed to follow the Hall-Petch equation, so timerelated grain growth correlates to a time-related drop in the tensile strength. Also, annealing was carried out to accelerate the evaluation of the time-related tensilestrength change. Thus, the copper deposits with high tensile strength after annealing can be judged to resist the time-related changes.

\section{Experimental}

\subsection{Plating test}

First of all, as a test to confirm the effect of the Mercapto group (Test A), electrolytes were prepared, to which each of 4 additives were added at concentrations of 0 to 105 $\mu \mathrm{mol} / \mathrm{dm}^{3}$, including 2 additives with Mercapto groups (2-Mercapto-Benzimidazole and 2-Mercapto-5-MethylBenzimidazole) and 2 additives without Mercapto groups (Benzimidazole and 2-Hydroxy-Benzimidazole). The composition of the base bath was: $\mathrm{CuSO}_{4} \cdot 5 \mathrm{H}_{2} \mathrm{O}: 1.26 \mathrm{~mol} / \mathrm{dm}^{3}$, $\mathrm{H}_{2} \mathrm{SO}_{4}: 1.43 \mathrm{~mol} / \mathrm{dm}^{3}, \mathrm{HCl}: 1.65 \mathrm{mmol} / \mathrm{dm}^{3}$, SPS: $168 \mu \mathrm{mol} /$ $\mathrm{dm}^{3}$, diaryl dimethyl ammonium chloride polymer (DDAC):433 $\mu \mathrm{mol} / \mathrm{dm}^{3}$ (as monomer), where DDAC is the cationic polymer surfactant, the structure of which is shown in Fig. 1, and is added as a suppressor similar to Polyethylenglycol (PEG), which is commonly used for the purpose of producing smooth surfaces with copper deposits.[7]

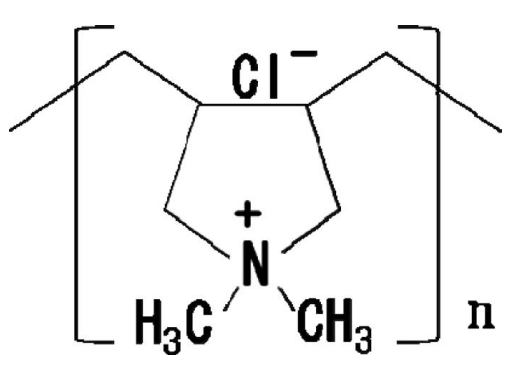

Fig. 1 Structure of diaryl dimethyl ammonium chloride polymer (DDAC).

Next, to confirm the effects of Nitrogen atoms and Benzene rings (Test B), we prepared electrolytes with nine different additives containing Mercapto groups and 0 to 4 Nitrogen atoms added at concentrations of 0 to $105 \mu \mathrm{mol} /$ $\mathrm{dm}^{3}$, including five additives without Benzene rings (3Mercapto-1-propanesulfonic-acid-sodium-salt, 2-Thiazoline2-thiol, 2-Mercapto-imidazole, 3-Mercapto-4-methyl-4H1,2,4-triazole, 5-Mercapto-1H-tetrazole-methanesufonic-acid) and four additives with Benzene rings (Thiosalicylic-acid, 2-Mercapto-benzothiazole-sodium-salt, 2M-5S, Sodium-3(5-mercapto-1H-tetrazole-1-yl) benzenesulfonate-monohydrate).

Using an $\mathrm{IrO}_{2}$ inert anode and a Ti plate cathode as electrodes, $12 \mu \mathrm{m}$ thick copper was plated at a bath temperature of 50 degrees Celsius and a current density of $50 \mathrm{~A} /$ $\mathrm{dm}^{2}$.

For the first evaluation, the tensile strength after annealing was measured for all copper deposits plated in both Test $\mathrm{A}$ and Test $\mathrm{B}$, and the correlation between that strength and the elements or groups contained in the additives was investigated.

Here, as mentioned above, annealing was carried out at 180 degrees Celsius for 1 hour in air to accelerate the timerelated property changes. Tensile strength was measured using a tensile tester (Shimadzu AG-1) following the method given in IPC-TM-650. The test specimen was 10 $\mathrm{mm}$ wide and $100 \mathrm{~mm}$ long and was made with a stampingout method. The specimen was held between the chucks $50 \mathrm{~mm}$ apart initially and measured by the strain rate of 50 $\mathrm{mm} / \mathrm{min}$.

Next we investigated the detailed effects of Nitrogen atoms and Benzene rings, and the $\mathrm{S}, \mathrm{C}, \mathrm{N}$ and $\mathrm{Cl}$ contents, which are components of SPS, DDAC and 2M-5S, in the copper deposits. The contents were measured and the correlation between those contents and the elements or groups contained in the additives, and between those contents and the tensile strength after annealing were investigated. In addition, this measurement of the contents of 
impurities was carried out on the deposits 2 weeks after deposition.

The $\mathrm{S}$ and $\mathrm{C}$ contents were measured using a $\mathrm{S}$ and $\mathrm{C}$ analyzer (Horiba EMIA-920V) by the method of high frequent heating combustion in oxygen flow - infrared spectroscopy. The $\mathrm{N}$ contents were measured using an $\mathrm{O}$ and $\mathrm{N}$ analyzer (Horiba EMGA-620). Samples were melted by impulse heating and their thermal conductivity measured. The $\mathrm{Cl}$ contents were measured by the following method: The copper deposits were dissolved in a nitric acid solution and deposits of $\mathrm{AgCl}$ were generated by adding $\mathrm{AgNO}_{3}$ to this solution. The absorbance of this solution was measured using an absorption spectrophotometer (Hitachi U3310) and the contents were calculated using the standard curve which was gained in advance.

\subsection{GD-OES analysis}

We next evaluated the time-related change of the impurities in the copper deposits. The $\mathrm{S}$ contents of 2 specimens which were newly plated with the same bath conditions (2M-5S addition $0 \mu \mathrm{mol} / \mathrm{dm}^{3}$ (base bath) and 70 $\mu \mathrm{mol} / \mathrm{dm}^{3}$ ) as in Test $\mathrm{B}$, were measured 10 minutes, 30 minutes, 60 minutes, 180 minutes and 1440 minutes (24 hours) after plating. The $\mathrm{S}$ contents were measured using Glow discharge optical emission spectrometry (GD-OES, Horiba JY5000RF) under the following conditions: pressure of $665 \mathrm{~Pa}$ after substituting Argon gas, power output of $30 \mathrm{~W}$, and analysis area $4 \mathrm{~mm}$ in diameter. Quantitative analysis of S was carried out using the strength of the 181 nm spectrum.

It is one of the merits of GD-OES to be able to measure the contents of elements in a short time. This test was carried out to measure the contents at specific points of time after deposition to investigate the time-related change of the contents.

\subsection{RRDE test}

Next, tests using a rotating ring-disc electrode (RRDE, Hokuto denko HR-201) were carried out for the purpose of investigating the behavior of the $2 \mathrm{M}-5 \mathrm{~S}$ in the electrolyte.

As a preliminary test, anodic polarization curves were measured on 2 solutions (potential scan rate, $0.01 \mathrm{~V} / \mathrm{sec}$ ) using a platinum rotating disc electrode (RDE). One solution was $1.43 \mathrm{~mol} / \mathrm{dm}^{3}$ sulfuric acid aqueous solution only, and the other was $1.43 \mathrm{~mol} / \mathrm{dm}^{3}$ sulfuric acid aqueous solution to which $2 \mathrm{M}-5 \mathrm{~S}: 70 \mu \mathrm{mol} / \mathrm{dm}^{3}$, SPS: $168 \mu \mathrm{mol} / \mathrm{dm}^{3}$ and DDAC: $433 \mu \mathrm{mol} / \mathrm{dm}^{3}$ (as monomer) were added (the temperature of both solutions was 50 degrees Celsius), to find the potential where additives themselves were oxidized. The SCE electrode was used as the reference and the rotation speed of $\mathrm{RDE}$ was set at $500 \mathrm{rpm}$ in this test. In the next test, the anodic polarization curves were measured on the 3 electrolytes shown below under the same measuring conditions as the preliminary test for the purpose of investigating the chemical compounds in the electrolytes.

The compositions of the 3 electrolytes were as follows: The first was $\mathrm{CuSO}_{4} \cdot 5 \mathrm{H}_{2} \mathrm{O}: 1.26 \mathrm{~mol} / \mathrm{dm}^{3}$ and $\mathrm{H}_{2} \mathrm{SO}_{4}: 1.43$ $\mathrm{mol} / \mathrm{dm}^{3}$ only ("No Additives bath" below): the next was $\mathrm{HCl}: 1.65 \mathrm{mmol} / \mathrm{dm}^{3}$, SPS:168 $\mu \mathrm{mol} / \mathrm{dm}^{3}$, DDAC:433 $\mu \mathrm{mol} / \mathrm{dm}^{3}$ (as monomer) added to the "No Additives bath" ("Without 2M-5S bath" bellow): and the last was 2M-5S:70 $\mu \mathrm{mol} / \mathrm{dm}^{3}$ added to the "Without 2M-5S bath" ("With $2 \mathrm{M}$ $5 \mathrm{~S}$ bath" bellow).

In addition, a RRDE test using a platinum rotating ringdisc electrode was carried out on the above 3 electrolytes (temperature on all solutions was 50 degrees Celsius). The disc potential was polarized in the cathodic direction at $0.01 \mathrm{~V} / \mathrm{sec}$ of scan rate and ring potential was kept at a constant value. In this test, 2 anodic potentials were used for the ring potentials, one was where additives are oxidized and the other was where additives were not oxidized, based on the above preliminary test. The SCE electrode was used as the reference electrode and the rotation speed of the RRDE was set at $500 \mathrm{rpm}$ in this test.

\section{Results and Discussion}

\subsection{Plating test}

The results of measuring the tensile strength after annealing of the copper deposits plated under each condition of Test A (maximum values for each condition) were as follows: The deposits from the two baths to which the additives with a Mercapto group were added, showed 848 $\mathrm{MPa}$ and $780 \mathrm{MPa}$ of tensile strength, and both deposits from the two baths to which the additives without Mercapto group were added, showed $300 \mathrm{MPa}$. As a reference, the deposit from the base bath showed $296 \mathrm{MPa}$, and the deposit from the 2M-5S-added bath showed $815 \mathrm{MPa}$. From this result, only the deposits from the baths to which the additives with a Mercapto group were added showed the same level of high tensile strength as those from the 2M-5S-added bath, and the additives with a Mercapto group were thought to be essential to prevent the timerelated property changes of deposits.

The correlation between the number of Nitrogen atoms contained in one molecule of the additives used in Test B and the tensile strength of the copper deposits after annealing (maximum values at each condition) is shown in 


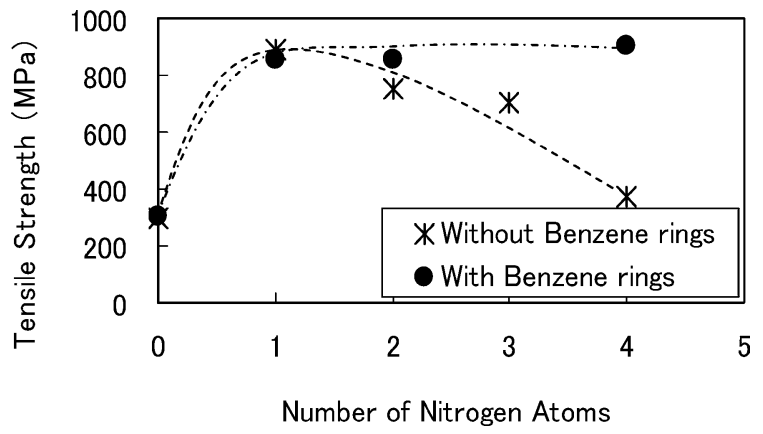

Fig. 2 Effect of Nitrogen atoms and Benzene ring contained in additives on tensile strength after annealing.

\section{Fig. 2.}

Even when the additives with a Mercapto group were used, when the number of Nitrogen atoms was 0 , high tensile strength could not be achieved whether they contained a Benzene ring or not. Moreover, the condition of the additive with one Nitrogen atom showed a peak value of tensile strength when no Benzene rings were contained in the additive. The conditions of the additives with one to four Nitrogen atoms showed the same level of high tensile strength when Benzene rings were contained in the additives. From these results, the additives with Nitrogen atoms are thought to be essential to prevent the timerelated property changes of the deposits. In addition, Benzene rings are thought not to be essential but to assist the effects of the Nitrogen atoms, widening the tolerance for the number of Nitrogen atoms required for the effect.

The correlation between the number of Nitrogen atoms contained in one molecule of additives used in Test $\mathrm{B}$ and the $\mathrm{S}, \mathrm{C}, \mathrm{N}$ and $\mathrm{Cl}$ contents in the copper deposits from the baths using each additive is shown in Fig. 3. In addition, these contents were measured on the deposits 2 weeks after deposition.

When the number of Nitrogen atoms contained in them was 0 , the contents were low whether they contain Benzene rings or not. Furthermore, the condition of the additive with one Nitrogen atom showed a peak value when no Benzene ring was contained in the additive. The conditions of the additives with one to four Nitrogen atoms showed high contents when Benzene rings were contained in the additives. It is conjectured that both Benzene rings and Nitrogen atoms showed an affection for the impurities contained in copper deposits, and the Benzene rings assisted the effects of the Nitrogen atoms.

The correlation of the contents of $\mathrm{S}, \mathrm{C}, \mathrm{N}$ and $\mathrm{Cl}$ of copper deposits in Test $\mathrm{B}$ measured 2 weeks after deposition and tensile strength after annealing (maximum values at

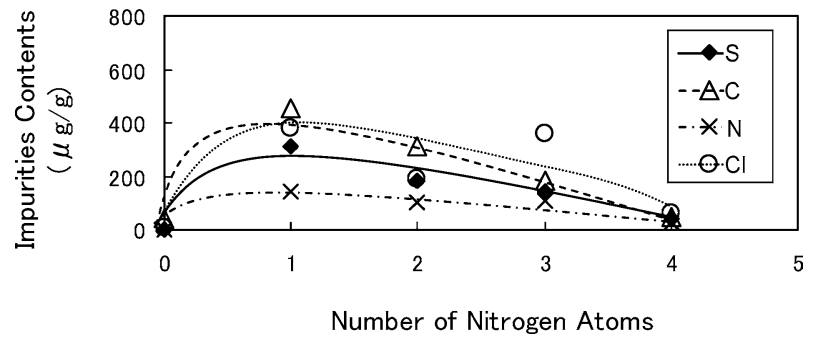

(1) Without Benzene rings.

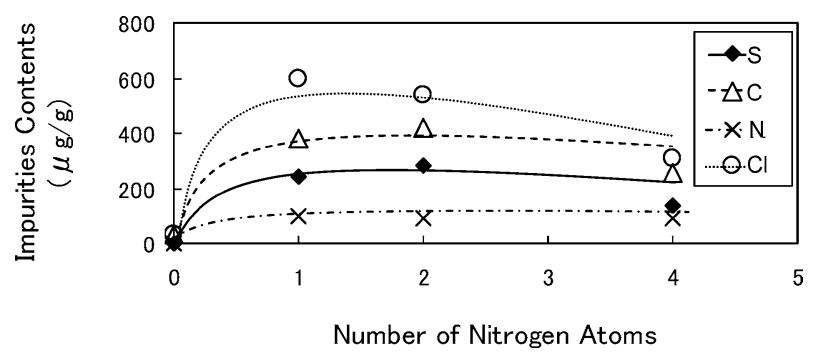

(2) With Benzene rings.

Fig. 3 Effect of Nitrogen atoms and Benzene ring contained in additives on $\mathrm{S}, \mathrm{C}, \mathrm{N}$ and $\mathrm{Cl}$ contents in copper deposits measured 2 weeks after deposition. (1) Without Benzene rings. (2) With Benzene rings.

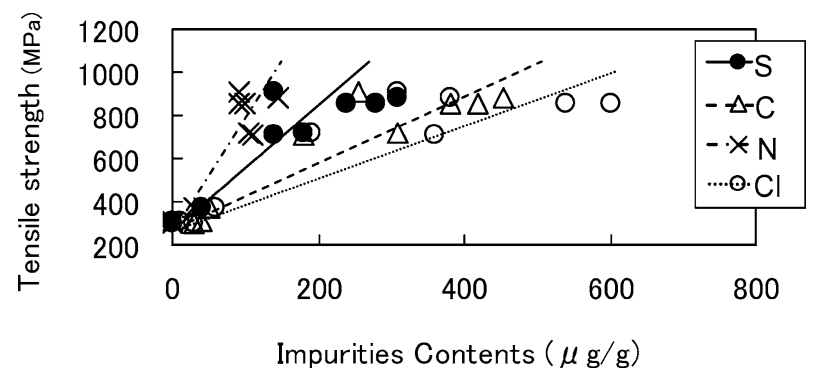

Fig. 4 Relation between $\mathrm{S}, \mathrm{C}, \mathrm{N}$ and $\mathrm{Cl}$ contents in copper deposits measured 2 weeks after deposition and tensile strength after annealing.

each condition) is shown in Fig. 4. These 2 factors showed a strong correlation, so the prevention of re-crystallization is thought to be affected by the contents of impurities contained in the deposits, which was the same as when the 2M-5S concentration in the bath was changed.

However, unlike the test in which the 2M-5S concentration was changed, the comparison in this test was among conditions in which only the number of Nitrogen atoms was changed while the numbers of Mercapto groups and Benzene rings were the same. From this result, it is thought that combination states with the copper ion in the electrolytes or coexisting other additives change when the number of Nitrogen atoms in one molecule of each additive are different, so that the contents of impurities incorporated into the deposits change. The detailed reaction 
mechanism will have to be elucidated in future, but it is conjectured that the high electronegativity of the Nitrogen atom causes the effect. In other words, it is thought that the density of electrons near the Nitrogen atom rises by polarization, and that it becomes easier to combine with copper ions or coexisting DDAC, which is a cationic polymer surfactant. So it is thought that impurities are incorporated into the deposits more easily when being reduced from the copper ion combined with these additives. In addition, it is thought that this combination becomes stronger when the density of electrons is higher, and that impurities can more easily be incorporated into deposits. It is conjectured that when there are fewer Nitrogen atoms in one molecule of the additive, more electrons can gather near one Nitrogen atom and a higher density of electrons can be achieved near the Nitrogen atom. In addition, it is conjectured that when the additives contain Benzene rings, the density of electrons can become much higher because of donating of the $\Pi$ electrons from the Benzene rings. These conjectures are based on the test results mentioned above.

\subsection{GD-OES analysis}

The time-related change of the $\mathrm{S}$ contents, measured using GD-OES, in copper deposits from just after deposition to 24 hours after deposition is shown in Fig. 5. These plots are the analysis data at a point etched $5 \mu \mathrm{m}$ from the freely grown side of copper deposits. Both deposits from the conditions of $0 \mu \mathrm{mol} / \mathrm{dm}^{3} 2 \mathrm{M}-5 \mathrm{~S}$ addition (base bath) and $70 \mu \mathrm{mol} / \mathrm{dm}^{3} 2 \mathrm{M}-5 \mathrm{~S}$ addition did not show a change in S contents from just-after-plated. So it is conjectured that the differences in the impurities contents shown in Fig. 3 are not generated after plating but are generated just at the time of plating. It is thought that this result does not contradict the consideration in the section 3.1 that the impurities contents incorporated into the copper deposits change because the combination state with copper ions or the other coexisting additives changes during plating due to

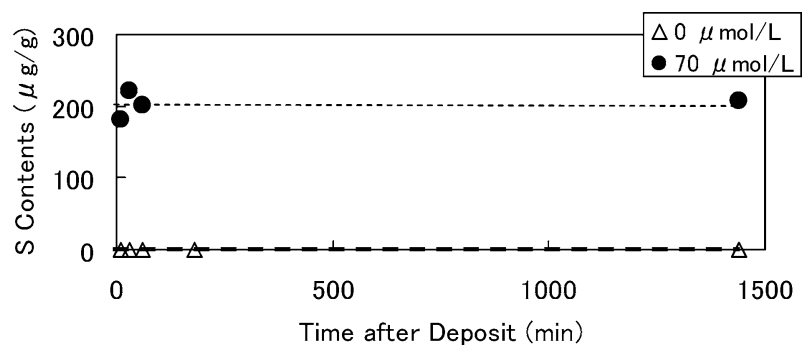

Fig. 5 Time-dependent change of $\mathrm{S}$ contents in copper deposits from $10 \mathrm{~min}$. to $1440 \mathrm{~min}$. (24 hours) after deposition measured using GD-OES. the conditions of the additives in the electrolytes.

\subsection{RRDE test}

First of all, the results of a preliminary test showed that the additives themselves were oxidized at potentials over $0.8 \mathrm{~V}$, so the ring potentials on the RRDE tests was set at $0.5 \mathrm{~V}$ and $0.9 \mathrm{~V}$.

The anodic polarization curves on the above 3 electrolytes, that is, No Additives bath, Without 2M-5S bath and With 2M-5S bath, are shown in Fig. 6. From these curves, the oxidation peak at approximately $1.2 \mathrm{~V}$ on the Without $2 \mathrm{M}-5 \mathrm{~S}$ bath did not appear on the With $2 \mathrm{M}-5 \mathrm{~S}$ bath. The chemical compounds detected at this potential were thought to disappear with the addition of $2 \mathrm{M}-5 \mathrm{~S}$, and this phenomenon is conjectured to show the change of chemical compounds as a result of the interaction of $2 \mathrm{M}-5 \mathrm{~S}$ with coexisting additives like DDAC.

The RRDE test results on the With 2M-5S bath are shown in Fig. 7. In addition to the ring potential curves of $0.5 \mathrm{~V}$ and $0.9 \mathrm{~V}$, which were set based on the preliminary test, the curve of the difference of ring currents (ring current at ring potential $0.9 \mathrm{~V}$ minus ring current at ring potential $0.5 \mathrm{~V}$ ) is shown. The $\mathrm{X}$ axis shows the disc potential, the left side of the $\mathrm{Y}$ axis shows the disc current density and the right side of the $\mathrm{Y}$ axis shows the ring current density.

A ring current with a ring potential of $0.5 \mathrm{~V}$ is thought to detect mainly $\mathrm{Cu}^{+}$ions. While changing the disc potential, $\mathrm{Cu}^{+}$ion intermediates were generated and showed a peak value near $0 \mathrm{~V}$ of disc potential. At a ring potential of $0.9 \mathrm{~V}$, a higher ring current was observed than that at $0.5 \mathrm{~V}$ condition and also showed a peak value at near $0 \mathrm{~V}$ of disc potential.

The difference in the currents at these 2 conditions were thought to detect the oxidation of the additives themselves as well as $\mathrm{Cu}$ (I) complexes derived from the additives, and

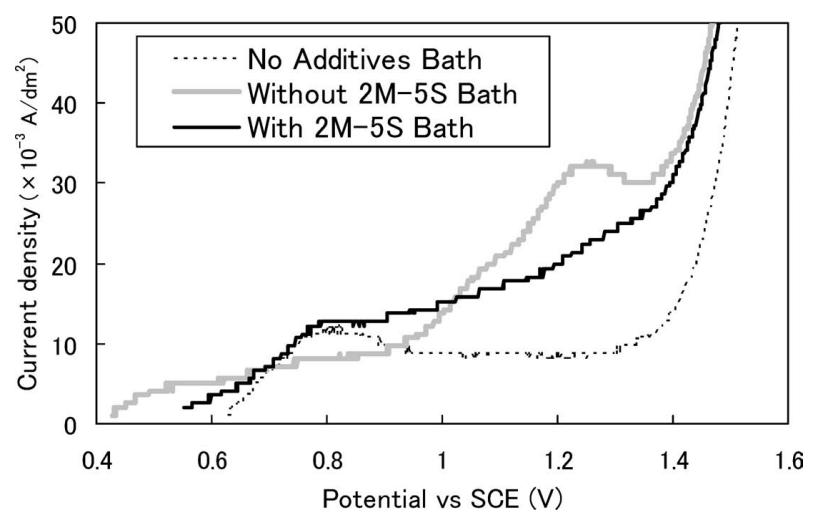

Fig. 6 Anodic polarization curves in various baths. 


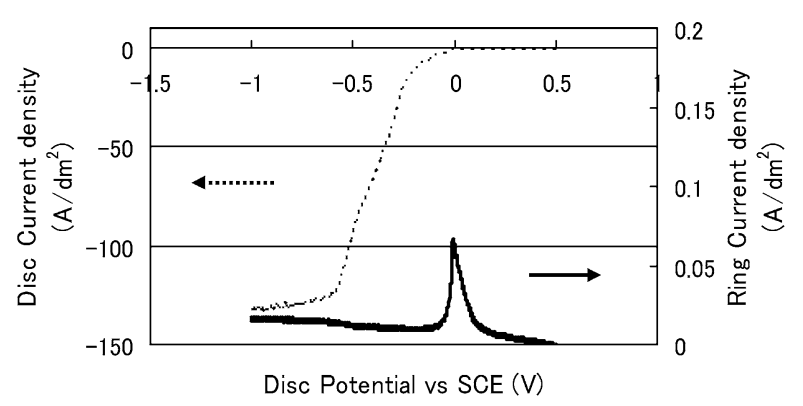

(1) Ring Potential $0.5 \mathrm{~V}$

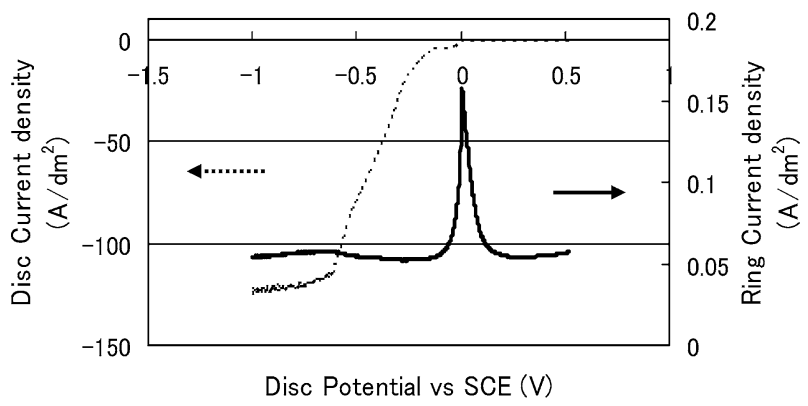

(2) Ring Potential $0.9 \mathrm{~V}$

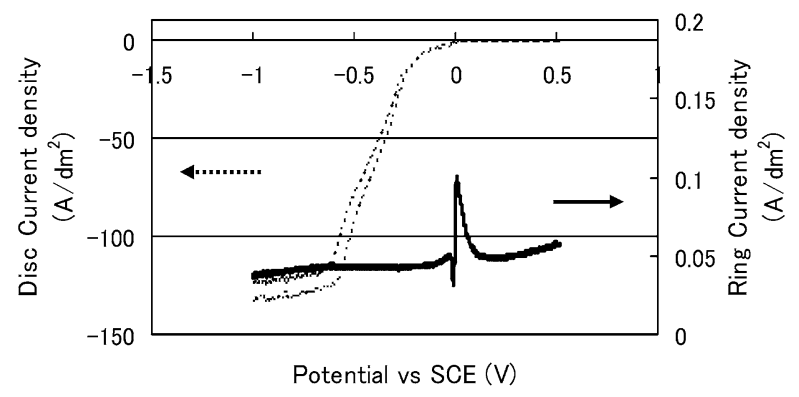

(3) Difference of Ring Current ( $\mathrm{I} 0.9 \mathrm{~V}-\mathrm{I} 0.5 \mathrm{~V}$ )

Fig. 7 RRDE test results in With 2M-5S bath. (1) Ring Potential 0.5 V. (2) Ring Potential 0.9 V. (3) Difference of Ring Current $\left(\mathrm{I}_{0.9 \mathrm{~V}}-\mathrm{I}_{0.5 \mathrm{~V}}\right)$.

also showed a peak value at near $0 \mathrm{~V}$ of disc potential. It is thought to be impossible that the amount of additives increases with changing disc potential, so the peak of the ring current difference is thought to show the increase of the amount of $\mathrm{Cu}$ (I) complexes. That is, the additives are thought to capture $\mathrm{Cu}^{+}$ion intermediates and generate $\mathrm{Cu}$ (I) complexes. As shown in Fig. 7, the peak value of the difference of ring currents was $0.1 \mathrm{~A} / \mathrm{dm}^{2}$ on the With $2 \mathrm{M}$ $5 \mathrm{~S}$ bath. With the same tests as above, the peak values on the Without 2M-5S bath and No Additives bath were 0.07 $\mathrm{A} / \mathrm{dm}^{2}$ and $0.03 \mathrm{~A} / \mathrm{dm}^{2}$.

From these results, the contribution of the $2 \mathrm{M}-5 \mathrm{~S}$ additive in generating $\mathrm{Cu}(\mathrm{I})$ complexes is estimated at the amount corresponding to $0.03 \mathrm{~A} / \mathrm{dm}^{2}\left(0.1-0.07 \mathrm{~A} / \mathrm{dm}^{2}\right)$ and $2 \mathrm{M}-5 \mathrm{~S}$ is conjectured to interact with $\mathrm{Cu}^{+}$ion intermediates in the electrolyte.
The results of the above RRDE tests, showing the possibility that $2 \mathrm{M}-5 \mathrm{~S}$ interacts with $\mathrm{Cu}^{+}$ions and additives like DDAC, are thought not to contradict the consideration in the section 3.1 that the contents of impurities incorporated into copper deposits change because, in plating, the combination state with copper ions or the other coexisting additives changes due to the conditions of the additives in the electrolytes.

From the above-mentioned test results, the mechanism of prevention of the time-related property changes by $2 \mathrm{M}-$ $5 \mathrm{~S}$ was conjectured as follows.

As it is known that SPS, which is well-known as brightener, is reduced in the electrolyte to 3-Mercapto-1propanesulfonic acid (MPS) containing a Mercapto group, and that MPS forms a $\mathrm{Cu}(\mathrm{I})$ complex due to the effect of Mercapto groups, $[3,8] 2 \mathrm{M}-5 \mathrm{~S}$ is thought to also form a $\mathrm{Cu}$ (I) complex due to an effect of Mercapto groups.

Because 2M-5S contains $\delta$-polarized Nitrogen atoms, which are not contained in SPS, the bonding strength of $2 \mathrm{M}-5 \mathrm{~S}$ with a $\mathrm{Cu}$ (I) complex is thought to be stronger than that of SPS due to the interaction close to the coordinate bond of the Nitrogen atoms. In addition, 2M-5S is thought to bond to a coexisting cationic polymer surfactant like DDAC using the $\delta$-polarized Nitrogen atoms, and produce a strong union with the $\mathrm{Cu}(\mathrm{I})$ complex and additives.

Therefore, the elements of SPS are thought to easily detached from copper when being reduced from the copper ion and are rarely incorporated into deposits, even though the $\mathrm{Cu}$ (I) complex shows its effects as an accelerator. In contrast, in the case of $2 \mathrm{M}-5 \mathrm{~S}$, additives are thought to continue bonding to copper even at the time of reduction and are incorporated into the deposits.

The impurities incorporated into the deposits due to the effect of 2M-5S are thought to be localized at the grain boundaries and to prevent the movement of the boundary and grain growth. Therefore, it is thought that high tensile strength can be maintained following the Hall-Petch equation.

\section{Conclusion}

The elements or groups contained in $2 \mathrm{M}-5 \mathrm{~S}$, which have effects for preventing the property changes of the copper deposited using some sort of additives in the bath, such as brighteners like SPS, were investigated. The results show that Mercapto groups and Nitrogen atoms seem to be essential. Benzene rings appear not to be essential but to assist the effects of the Nitrogen atoms, broadening the tolerance of the number of Nitrogen atoms required for 
the effects.

These elements are thought to prevent time-related property changes by increasing the amount of impurities incorporated into the deposits at the time of deposition.

$2 \mathrm{M}-5 \mathrm{~S}$ is thought to produce a strong union with a $\mathrm{Cu}(\mathrm{I})$ complex and coexisting additives using the $\delta$-polarized Nitrogen atoms and to increase the amount of impurities incorporated at the time of reduction.

\section{References}

[1] T. Yamamoto and N. Inoue, Electronic Parts and Materials, Vol. 45, No. 10, pp. 25-28, 2006.

[2] N. Ogawa, K. Kamiyama, T. Tanabe, H. Onozeki and T. Kumakura, "Profile-Free Copper Foil for Fine Printed Wiring Boards”, Hitachi Chemical Technical Report, Vo. 46, pp. 15-18, 2006.

[3] P. M. Verrecken, R. A. Binstead, H. Deligianni and P. C. Andricacos, "The chemistry of additives in damascene copper plating”, IBM J. Res. \& Dev., Vol. 49, No. 1, pp. 3-18, 2005.
[4] H. Abe, A. Kondo and T. Watanabe, "Age Softening Phenomenon of Electrodeposited Copper Plating Film”, J. Japan Inst. Metals, Vol. 68, No. 9, pp. 844850, 2004.

[5] K. Yamanishi, "Treated Rolled Copper Foil for Flexible Printed Circuit Board”, J. of Japan Inst. of Electronics Packaging, Vol. 7, No. 5, pp. 428-432, 2004.

[6] M. Matsuda, H. Yoshihara and M. Dobashi, "Prevention of Physical Property Changes While Being Kept at Room Temperature on the Electroplated Copper”, J. Surf. Finish. Soc. Jpn, Vol. 59, No. 10, pp. 696-700, 2008.

[7] M. Matsuda, H. Sakai, S. Tomonaga and M. Dobashi, JP2007-217788, 2007.

[8] E. E. Farndon, F. C. Walsh and S. A. Campbell, "Effects of Thiourea, Benzotriazole and 4,5-dithiaoctane1,8-disulfonic Acid on the Kinetics of Copper Deposition from Dilute Acid Sulfate Solutions”, J. Appl. Electrochem., Vol. 25, No. 5, pp. 574-583, 1995. 